\title{
Effects of Different Planting Modes on Peanut Photosynthetic Characteristics, Leaf Area Index and Yield in the Sandy Area
}

\author{
Huixin Wang ${ }^{1,2, a}$ \\ ${ }^{1}$ Shenyang Agricultural University \\ 2 Liaoning Academy of Agricultural Sciences Shenyang, \\ China \\ 357904670@qq.com \\ Yifei Liu ${ }^{1, a}$ \\ ${ }^{1}$ Shenyang Agricultural University \\ Shenyang, China \\ liuyifeiscience@163.com \\ Qiaobo Song $^{1}$ \\ ${ }^{1}$ Shenyang Agricultural University \\ Shenyang, China \\ 13889220763@163.com
}

\author{
Yan $\mathrm{Lu}^{1}$ \\ ${ }^{1}$ Liaoning Academy of Agricultural Sciences Shenyang, \\ China \\ 95174006@qq.com
}

a Joint first authors
* Corresponding author

\author{
Qingwen $\mathrm{Shi}^{1}$ \\ ${ }^{1}$ Shenyang Agricultural University \\ Shenyang, China \\ feifan61@gmail.com
}

\begin{abstract}
Five planting modes were designed to study photosynthetic characteristics, leaf area index and yield of peanut variety as Fu Hua 17 in order to provide theoretical basis for peanut yield increase in the sandy area. Results showed that the mode of peanuts planted for double rows in the border check with mulched drip irrigation (T1) was the best. The second was the mode with single grain planted and staggered for double rows in the bare ridge (T2). The order for the yield from the highest to the lowest for the five modes was: those planted for double rows in the border check with mulched drip irrigation (T1) > those with single grain planted and staggered for double rows in the ridge (T2) > those planted and densified in the narrower ridge (T3) $>$ those planted for three rows in the border check (T4) $>$ those as normally planted in the bare field (CK). Therefore, the planting mode of double rows in the border check with mulched drip irrigation (T1) and the mode of single grain planted and staggered for double rows in the bare ridge (T2) were better for the sandy area.
\end{abstract}

Keywords-planting mode; photosynthetic characteristics; canopy structure; peanut yield

During the recent years, many domestic scholars attached more and more importance to high-yield colony structure in the crop high-yield cultivation[1,2]. They maintained that yield increase could be achieved by improving ventilation and light penetration for the population as far as possible[3-5], as well as by improving LUE (light utility efficiency) on the premise of satisfying soil, fertilizer and water. A few studies showed that tillage methods could not only improve colony structure, but also improve soil microenvironment[6]. At present, many scholars have done more researches on different planting density for peanuts, whereas most were limited to the planting mode of the same species [7-10]. Peanuts with different density gradients in different planting modes were studied in the experiment. With the help of the dynamic changes analysis in photosynthetic rate, content of chlorophyll (SPAD) and leaf area index (LAI) for peanut treatments, comprehensive analysis were assumed finally in combination with the yields to offer scientific basis for selecting favorable planting density and planting modes in the sandy semiarid region.

\section{MATERIALS AND METHODS}

\section{A. Experimental area situation}

The experiment was designed in Zhanggutai station of Liaoning Academy of Agricultural Sciences. The station lies at north latitude $42^{\circ} 42^{\prime}$, east longitude $122^{\circ} 32^{\prime}$ and height 213.1 meters. The cropped soil is loam soil, with organic content, available nitrogen, available phosphorus, available potassium and $\mathrm{pH}$ as $27.4 \mathrm{~g} / \mathrm{kg}, 143$ $\mathrm{mg} / \mathrm{kg}, \quad 66.0 \mathrm{mg} / \mathrm{kg}, 108 \mathrm{mg} / \mathrm{kg}$, and 5.6 respectively. The frostless season is $150-155$ days. The active accumulated temperature $\left(\geqq 10^{\circ} \mathrm{C}\right)$ is $3468^{\circ} \mathrm{C}$. The average temperature annually is $6.82^{\circ} \mathrm{C}$. The annual precipitation is $500-520 \mathrm{~mm}$, most in July and August frequently. Annual evaporation is about $1600-1800 \mathrm{~mm}$. Dryness is about 4.0 , as that in a semi arid region, where spring 
drought, summer drought and autumn hanging occurs, or spring drought, summer drought and autumn hanging occurs alternately [2].

\section{B. Experiment design}

This experiment was designed in the sandy soil with Fuhua17 as variety. Four treatments were specified, with an additional treatment as normally planted as control check (CK).

T1 represented those planted with mulched drip irrigation. Peanuts were planted as mulched for double rows in the border check. The top width of the border was $65 \mathrm{~cm}$, the bottom width $95-100 \mathrm{~cm}$, and the height was $10-$ $20 \mathrm{~cm}$. There are two rows for furrow planting with row spacing of $35 \mathrm{~cm}$, where in the drip belts were paved, row spacing $9 \sim 10 \mathrm{~cm}$ for single-seed planting [13$14]$ with the density of $14000 / 667 \mathrm{~m} 2$.

$\mathrm{T} 2$ represented single grain planted and staggered for double rows in the bare ridge. The ridge spacing was $60 \mathrm{~cm}$, and the furrow spacing was $15 \mathrm{~cm}$, and $14-15 \mathrm{~cm}$ spacing for single-grain planting as staggered with the density of $16000 / 667 \mathrm{~m} 2$.

T3 represented those planted and densified in narrower ridge. The ridge spacing was $45 \mathrm{~cm}$. Single peanut grain was planted with plant spacing $7-8 \mathrm{~cm}$ with density of $18000 / 667 \mathrm{~m} 2$.

$\mathrm{T} 4$ represented those planted for three rows in the bare border check. The top width of the border was $100-105 \mathrm{~cm}$, and the bottom width was $120 \mathrm{~cm}$ for three rows of peanuts. The spacing of the border was $30 \mathrm{~cm}$. Single peanut grain was planted with plant spacing $7-8 \mathrm{~cm}$, row spacing $30-$ $35 \mathrm{~cm}$ with the density of $20000 / 667 \mathrm{~m} 2$.

T5 represented those normally planted (CK). The ridge spacing was $60 \mathrm{~cm}$. Single peanut grain was planted with plant spacing $9-10 \mathrm{~cm}$ with the density of $12000 / 667 \mathrm{~m} 2$. $50 \mathrm{~kg}$ slow release fertilizer special for peanut, $10 \mathrm{~kg}$ complex fertilizer special for peanut and $1 \mathrm{~kg}$ plural micro fertilizer were applied to peanuts per $667 \mathrm{~m} 2$. Each treatment was under sprinkling irrigation twice during pod swelling and maturity period (T1 under drip irrigation, however) to ensure normal need for water by peanuts in mid-later period, and the other field management was identical.

\section{Study method}

\section{1) Measurement of photosynthetic indices}

We measured photosynthetic rate $\left(\mathrm{Pn}, \mu \operatorname{molm}^{-2} \cdot \mathrm{s}^{-1}\right)$ and transpiration rate $\left(\mathrm{Tr}, \mathrm{mmol} \bullet \mathrm{m}^{-2} \cdot \mathrm{s}^{-1}\right)$ and other major physiological indices and environment factors for peanuts with Licor-6400 (American, made by LI-COR company) in the pod swelling period (mid-August). Testing time was specified to be around AM10:00. We selected healthy plants with similar growth, as well as those healthy leaves with full stretch, free from pests and diseases in the test. Each index was measured for 3 repetitions, 3 data for each repetition before the average was taken.

\section{2) Content chlorophyll and LAI}

Fine windless weather was selected respectively in peanut seedling growth, flowering, acicular formation, pod swelling and maturity period, and then a hand-held portable SPAD.502 chlorophyll meter made in Japan was used to measure SPAD values in vivo for leaves, which were selected from each plot to determine their photosynthetic parameters. In the test, we need to avoid vein, and we only take the average value of the bottom, middle and top leaves. Then the leaf area indices were calculated by measuring transmittance of radiation with LAI-2000.

3) Method of analysis and calculation

\section{RESULTS AND ANALYSIS}

\section{A. The change of the peanut photosynthetic rate for different modes}

The order from the highest to the lowest for photosynthetic rate of different modes is $\mathrm{T} 1>\mathrm{T} 2>\mathrm{T} 3>$ $\mathrm{T} 5>\mathrm{T} 4$ in the pod swelling and mature phases according to Figure one. The mode of T1 enjoyed a coordinated colony structure and reasonable density. With mulched drip irrigation, T1 could preserve water and fertilizer, so that the peanuts could absorb more water and fertilizer. Though T2 is of a planting mode on bare land, its photosynthetic rate showed no remarkable difference from that of $\mathrm{T} 1$, mostly because $\mathrm{T} 2$ also enjoyed a coordinated colony structure spatially, due to its staggered planting mode for single grain in two rows on the ridge. All would mitigate conflicts among plants for more fertilizer and water, for more space as well, so $\mathrm{T} 2$ photosynthetic rate was much striking.

In addition, the photosynthetic rate in mature period decreased obviously than that in the pod swelling period for every mode equally, for the leaves in the mature period were aging, especially those in the lower part and those in the upper part even suffered from reduced physiological function. T5 declined mostly, and it was maybe because of its planting mode as three rows on the border check with higher density, leading to less ventilation and light penetration for closed peanut population. Meanwhile sandy soil is poorer at preserving water and fertilizer, so when conflicts among peanuts for more water and fertilizer appeared, the physiological indices such as photosynthetic capacity for a colony declined.

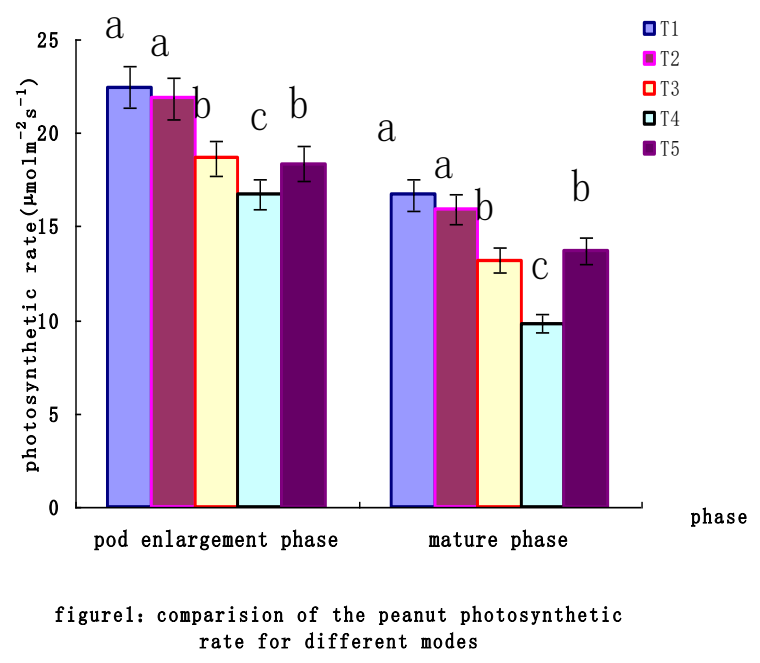




\section{B. Dynamic changes of SPAD for chlorophyll about different modes}

Since there was less need for water and fertilizer for early growth, no obvious difference was found about SPAD for the five modes in peanut early growth stage according to Figure two. However, with more need for water and fertilizer from the peanut colony in mid-later stage, obvious difference appeared in SPAD. The SPAD of $\mathrm{T} 1$ and $\mathrm{T} 2$ were higher than others in acicula formation and pod swelling period, as both vital to peanut growth and development. The SPAD of the other three treatments decreased continuously in mid-later stage of growth, especially for $\mathrm{T} 4$.

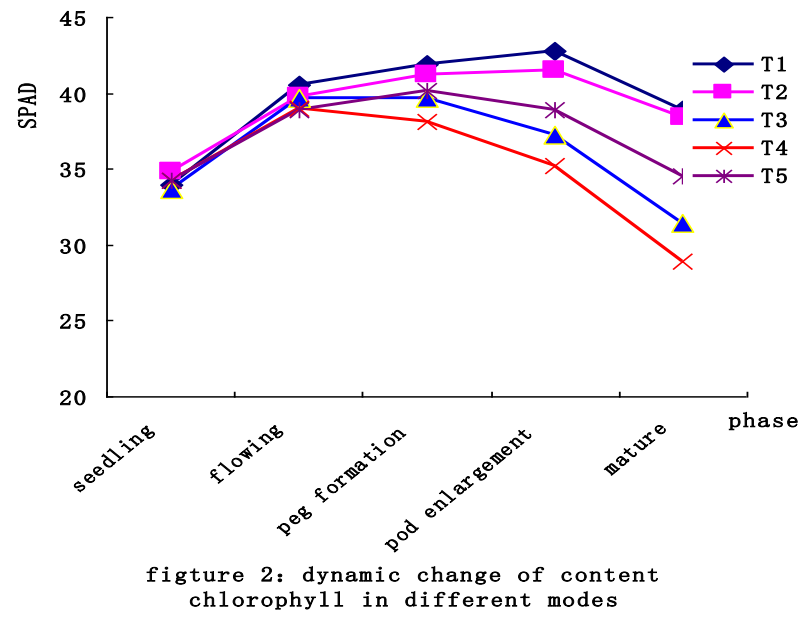

\section{Dynamic changes of Peanut LAI in different modes}

According to Figure three, we found that dynamic changes of LAI for T1 was the best, and those for T2 were better. Though T4 LAI remained higher during early period, it distinctively showed earlier senescence in the later period, mostly because of its higher density for peanuts to compete for more water and fertilizer. Therefore LAI declined remarkably till the mature period. T5 LAI stayed lower during the whole growth period, mostly due to larger row spacing and lower density on the bare land, so it was hard to make full crop available for peanuts in mid-later period, and the yield was eventually affected.

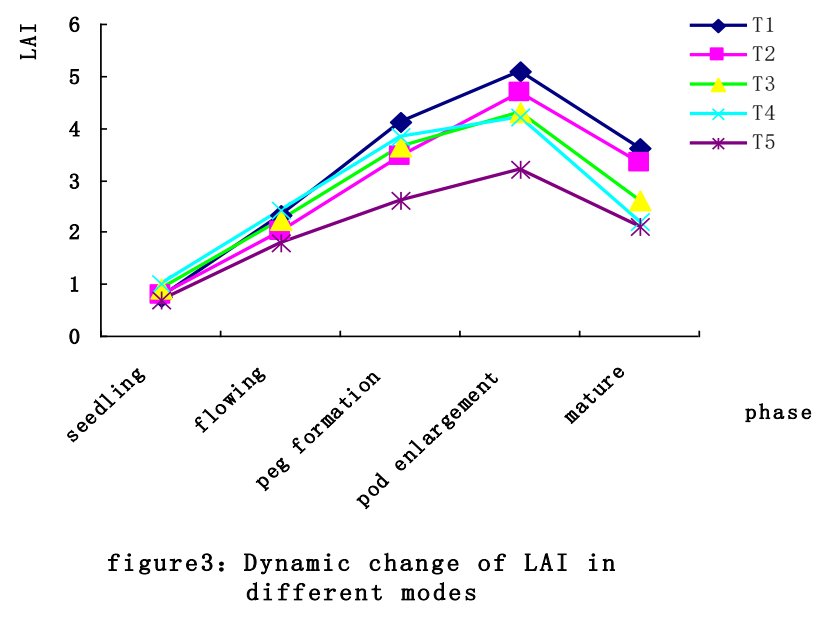

\section{Changes in correlated characteristics and yield for peanuts of different planting modes}

The agronomic characteristic of $\mathrm{T} 1$ and $\mathrm{T} 2$ base on Table one were better than others. They were different significantly from other treatments, and $\mathrm{T} 1$ yield was $342.8 \mathrm{~kg} / 667 \mathrm{~m} 2$, T2 yield $310.8 \mathrm{~kg} / 667 \mathrm{~m} 2$. The density of $\mathrm{T} 3$ and T4 was higher, so there were less ventilation and light penetration for their population in the field, and branching number declined at the same time, especially for $\mathrm{T} 4$, whose higher density led to noted conflicts among the colony for more water and fertilizer, so its yield was lower. Although agronomic characteristic of T5 were better than those for $\mathrm{T} 3$ and $\mathrm{T} 4$, it featured a lower yield due to its lower density.

TABLE I. AGRONOMIC CHARACTERS AND YIELD OF DIFFERENT MODES

\begin{tabular}{ccccccccc}
\hline mode & $\begin{array}{c}\text { main } \\
\text { stem } \\
\text { height } \\
(\mathrm{cm})\end{array}$ & $\begin{array}{c}\text { side } \\
\text { branches } \\
\text { length } \\
(\mathrm{cm})\end{array}$ & $\begin{array}{c}\text { Total branch } \\
\text { number } \\
(\text { number/plant } \\
)\end{array}$ & $\begin{array}{c}\text { full-pod number } \\
(\text { number/plant })\end{array}$ & $\begin{array}{c}\text { yield } \\
\text { per } \\
\text { plant } \\
(\mathrm{g})\end{array}$ & $\begin{array}{c}100 \text {-grain } \\
\text { weight } \\
(\mathrm{g})\end{array}$ & $\begin{array}{c}100 \text {-seed } \\
\text { weight } \\
(\mathrm{g})\end{array}$ & $\begin{array}{c}\text { yield } \\
(\mathrm{kg} / 667 \mathrm{~m} 2\end{array}$ \\
\hline $\mathrm{T} 1$ & $36.3 \mathrm{a}$ & $38.9 \mathrm{a}$ & $9.4 \mathrm{a}$ & $24.7 \mathrm{a}$ & $24.1 \mathrm{a}$ & $197.5 \mathrm{a}$ & $75.5 \mathrm{a}$ & $342.8 \mathrm{a}$ \\
$\mathrm{T} 2$ & $35.4 \mathrm{a}$ & $38.4 \mathrm{ab}$ & $8.5 \mathrm{~b}$ & $23 \mathrm{a}$ & $19.8 \mathrm{~b}$ & $187.1 \mathrm{~b}$ & $74.2 \mathrm{~b}$ & $310.8 \mathrm{~b}$ \\
$\mathrm{~T} 3$ & $32.4 \mathrm{~b}$ & $35.7 \mathrm{c}$ & $7.6 \mathrm{c}$ & $18.7 \mathrm{~b}$ & $15.6 \mathrm{c}$ & $173.6 \mathrm{c}$ & $70.5 \mathrm{~d}$ & $282.3 \mathrm{c}$ \\
$\mathrm{T} 4$ & $28.7 \mathrm{c}$ & $34.6 \mathrm{~d}$ & $6.7 \mathrm{~d}$ & $14.8 \mathrm{c}$ & $12.7 \mathrm{~d}$ & $167.8 \mathrm{~d}$ & $72.8 \mathrm{c}$ & $249.8 \mathrm{~cd}$ \\
$\mathrm{~T} 5$ & $32.5 \mathrm{~b}$ & $36.8 \mathrm{bc}$ & $9.5 \mathrm{a}$ & $20.1 \mathrm{~b}$ & $19.7 \mathrm{~b}$ & $186.7 \mathrm{~b}$ & $72.7 \mathrm{c}$ & $239.6 \mathrm{~d}$
\end{tabular}

\section{DISCUSSION AND CONCLUSION}

A. The order from the highest to the lowest for photosynthetic rate of different modes is :T1 $>\mathrm{T} 2>\mathrm{T} 3>$ $\mathrm{T} 5>\mathrm{T} 4$ in the pod swelling and mature phases. The photosynthetic rate in mature period decreased obviously than that in the pod swelling period for every planting mode. Some concerned researches showed that the larger population density with serious shading for each other would limit light projection, and even distribution in the colony. Therefore, the lower leaves were often below the light compensation points, and LUE is lower for the colony, so photosynthetic rate was also affected . [1,11] 
B. The SPAD of T1 and T2 was higher than others in acicula formation and pod swelling period. Some concerned researches showed that higher chlorophyll content would ensure better physiological indices (such as photosynthetic capacity) to accelerate dry matter formation and its reasonable contribution, rather influential on a better yield[12]. The SPAD of the other three treatments decreased continuously in mid-later growth stage, especially for T4. It was because T4 was a planting mode with higher density for three rows in the furrow, so there was great need for water and fertilizer in the mid-later period, and more conflicts for water and fertilizer resource on the ground or under the ground among individual plants were strongly sensed, so fertilizer shortage easily appeared during late period, leading to leaf chlorosis and affecting photosynthesis and yield furthermore.

C. The leaf area index became higher as the density was increasing in a certain range of planting density. However, higher leaf area index would cause shorter fastgrowing period due to serious leaf shading. After the fastgrowing period, leaves at the lower part would fall rapidly, so dry mater accumulation was affected during later period, and pod plumpness was affected as well[13]. We found that dynamic changes of LAI in T1 were the best, for the mulch could retain water and fertilizer during the whole growth period to offer sufficient water and fertilizer for peanuts in such a period, so LAI stayed favorable all the while for T1. Secondly for T2, as a planting mode of single grain staggered for two rows on the bare ridge, it enjoyed more reasonable spatial layout for better utilization of light energy, and for better utilization of water and fertilizer to some extent. T5 is a normal planting mode (CK), whose LAI remained lower during the whole growth period, for the traditional planting mode featured wider spacing and lower density, so it was hard to make full crop available and the land use rate was not high. Since these plants were not staggered individually, the spatial layout proved to be not reasonable for better light energy utilization. Thus its LAI remained lower during the whole growth period.

D. The order for the yield of the five modes was: those planted for double rows in the border check with mulched drip irrigation (T1) $>$ single grain planted staggered for double rows in the ridge (T2) $>$ those planted and densified in the narrower ridge (T3) $>$ those planted for three rows in the border check (T4) $>$ those normally planted in bare land $(\mathrm{CK})$. T1 yield and $\mathrm{T} 2$ yield were higher due to heir reasonable density with better spatial layout and mulched drip irrigation to retain water and fertilizer for more optimal conditions. T2 is a planting mode with single grained staggered in the bare land, and the plant canopy enjoys desirable layout spatially. Some concerned researches showed that we could have a better yield by reducing density when water and fertilizer are favorable, because of the automatic regulation of plant colony (demonstrated in such aspects as pod of per plant, pod weight, physiological character etc as well). Too large or small density was not favorable equally to the formation of constitutive factors for peanut yield. In case of lower density, individual plant would grow strongly with more pods for each, but the proportion of young pods and immature pods rose accordingly, and pod plumpness and maturity declined, too. In case of higher density, individual plant would grow poorly, and the pods would be immature due to lack of nutrients. Reasonable density for a planting mode will allow well developed individuals with good fruiting, coordinated development between the colony and individuals for bigger and plumper pods[1,12]. According the comprehensive comparison, we thought that the mode of planting for double rows in the border check with mulched drip irrigation and single grain planted and staggered for double rows in the bare ridge were better for this area.

\section{ACKNOWLEDGMENT}

The research work was supported by National Natural Science Foundation of China under Grant No. 31301842 , Key Project of Science and Technology of Liaoning under Grant No. 2014201007, China Postdoctoral Science Foundation under Grant No. 2012M510839 and 2014T70262, the Doctoral Scientific Fund Project of the Ministry of Education of China under Grant No. 20122103120011, Cultivation Plan for Youth Agricultural Science and Technology Innovative Talents of Liaoning Province under Grant No. 2014043, National Natural Science Initial Foundation of Shenyang Agricultural University under Grant No. 20112013, Postdoctoral Science Foundation of Shenyang Agricultural University under Grant No. 105110, Tianzhu mountain talents support program of SYAU and the Earmarked Fund for China Agriculture Research System under Grant No. CARS-14.

\section{REFERENCES}

[1] Wan Shubo. Chinese peanut cultivation. Shanghai Science and Technology Press, 2003.

[2] Wang Huixin, Wu zhanpeng, Su junwei. Research on density of single-double grain planted in semi-drought area. Chinese journal of oil crop sciences. 35, pp. 92-96, 2013.

[3] Paxton Payton. Kameswara Rao Kottapalli. Gene expression profiling in peanut using high density oligonucleotide microarrays. BMC Genomics. 10, pp. 265-267, 2009.

[4] Luo M., Liang XQ., Dang P., Holbrook CC., Bausher MG., Lee RD., Guo BZ. Microarray-based screening of differentially expressed genes in peanut in response to Aspergillus parasiticus infection and drought stress. Plant Sci., 169, pp. 695-703, 2005.

[5] Liu YF, Han XR, Zhan XM, Yang JF. Regulation of calcium on peanut photosynthesis under low night temperature stress. J. Integra. Agric. 12, pp. 2172-2178, 2013.

[6] Luo honghai, Zhang wangfeng, Zhao ruihai. Affecting on population photosynthetic rate, canopy structure and yield with the mulched drip irrigation by planting density in Xinjiang. Chinese journal of ecological agriculture, 14, pp. 112-115, 2006.

[7] Liu YF, Qi HY, Bai CM, et al. Grafting helps improve photosynthesis and carbohydrate metabolism in leaves of muskmelon. Int. J. Biol. Sci. 7, pp. 1161-1170, 2011.

[8] Liu YF, Li TL, Qi HY, et al. Effects of grafting on carbohydrate accumulation and sugar-metabolic enzyme activities in muskmelon. Afr. J. Biotechnol. 9(1), pp. 25-35, 2010.

[9] Cecilia M., Tojo Soler., Ayman Suleiman., Jakarat Anothai., Ian Flitcroft., Gerrit Hoogenboom. Scheduling irrigation with a dynamic crop growth model and determining the relation between simulated drought stress and yield for peanut. Irrig. Sci., 31, pp 889-901, 2013. 
[10] Kiniry JR., Simpson CE., Schubert AM., Reed JD. Peanut leaf area index, light interception, radiation use efficiency, and harvest index at three sites in Texas. Field Crop Res., 91, pp. 297-306, 2005.

[11] Li qinghua, Huang jintang, Chen hailing. Study on main coordinative relations of agronomic characters of peanut. Journal of peanut science, 37, pp. 40-44, 2008.
[12] Li qinghua. Analysis about agronomic characters of peanut yield in different habitats. Journal of peanut science, 38, pp. 36-40, 2009.

[13] Joseph C., V. Vu. Acclimation of peanut (Arachis hypogaea L.) leaf photosynthesis to elevated growth $\mathrm{CO} 2$ and temperature. Environmental and Experimental Botany, 53, pp. 85-95, 2005. 